\section{New Chemistry Building at University of Leeds}

Sir Frederick Gowland Hopkins, president of the Royal Society, formally opened the new chemistry building at the University of Leeds, on January 12, in the presence of the Pro. Chancellor of the University, Col. C. H. Tetley, the Vice-Chancellor, Sir James Baillie, and a representative gathering of past and present members of the University and of visitors from other universities. Sir Frederick Hopkins, in an address entitled "Modes of Thought in Chemistry", stressed the im. portance of chemical knowledge for national progress and emphasised the importance of experimental inquiry in pure chemistry, one of the fundamental sciences. In a critical and stimulating discussion of the differences in the habits of thought of workers in the several sections of pure chemistry, he dwelt on the great results which have been achieved especially in organic chemistry by the use of a mode of thought essentially pictorial and non-mathematical, which is as necessary as the more quantitative methods of the physical chemist. After the ceremony in the large lecture theatre, an inspection was made of the new laboratories. The rapid growth of the Department under Prof. Arthur Smithells, who succeeded Sir Edward Thorpe and by whose efforts the chairs of organic and physical chemistry were instituted, called for an extension of space but for many years the only quarters available were buildings of a tem. porary nature and geographically separated. Now, thanks to the generous response of the public and the policy of the University Council, all the various sections of pure chemistry have been gathered together under one roof in a new building facing Woodhouse Lane, which forms the latest addition to the general scheme for the extension of the University of Leeds.

\section{Ball Lightning}

Prof. J. C. Jensen, of Nebraska Wesleyan University, Washington, describes in Physics, vol. 4, October, 1933, how he was fortunate enough to photograph ball lightning when he was taking photographs of ordinary lightning in an August thunderstorm. The display of lightning was taking place in the region of the outrushing cold squall in advance of the main mass of the storm, and this squall was carrying with it great quantities of dust. In the wake of one of the flashes came the globular lightning, apparently floating slowly downwards. Two or three brilliant globular structures of the kind known as ball lightning appeared to travel along a pair of high-voltage power lines for a considerable distance, eventually falling to the ground and disappearing with a loud report. Two are clearly visible on one of the photographs, and, as their distance was known, it was an easy matter to determine their diameters, which were found to be very much larger than numerous observations of the phenomenon made elsewhere would have led one to expect, namely, $28 \mathrm{ft}$. and $42 \mathrm{ft}$. Unfortunately, ball lightning is so rare compared with ordinary lightning that the much desired confirmatory evidence of the occurrence of such large globular structures that might result from further photographs may be a long time in coming. There seems no doubt from the repeated observations of ball lightning made inside houses, and from the size of holes made by it through window-panes, that it is generally much smaller.

\section{Mind, Brain and Survival}

Dr. Wrultam Brown, lecturing on "Modern Science and the Possibility of Survival", at the Survival League at Caxton Hall on January 11, discussed the various theories of relation of mind to brain, and expressed the view that nothing firmly established in modern science makes personal survival after bodily death intellectually inconceivable. But the task of obtaining reliable evidence is beset with enormous difficulties. The results and messages in mediumistic trance should be closely scrutinised in the light of modern knowledge of the psychology of the unconscious, and sifted with due regard to the statistical laws of chance coincidence. Spontaneous psychic experiences on the part of private individuals, though more reliable in other respects, are specially difficult to assess statistically. There is little doubt that a large proportion of the apparent evidence for survival has to be rejected by strict science; but when all the sifting has been done there remains a small residuum very difficult to explain. Phenomena can only be fitted into a scientific system if their conditions of causation are known, and this is far from being the case with psychic phenomena, although some of the more general conditions are being gradually revealed. Very thoroughgoing psychological analysis of selected mediums will advance our knowledge considerably in this dim borderland of science, and may indicate further lines of investigation.

\section{Administration and Management in Industry}

THE number of societies and institutions dealing with the administrative or managerial side of industry is now very considerable and covers a wide and varied field in works management, costing, salesmanship, advertising, research, etc. That there is plenty of work and scope for organisations of this sort is evident enough, but there is certainly some ground for supposing that their number may soon become excessive, and some at least may be unable to obtain sufficient financial support to keep going, especially since the subscription rates are necessarily rather high and correspondingly onerous to manufacturers and their executives in these difficult times. From its name, the Institute of Industrial Administration should be capable of covering the whole territory, but it has many rivals. It is to be hoped there is room for all, and that there will be no desperate struggle for survival. The Institute held its annual general meeting on December 12, and an increase in the subscription of corporate members from 3 guineas to 5 guineas was recommended. This is to be interpreted, we hope, as a measure of increased usefulness to members rather than as an expiring clutch for more funds. The papers presented at the 1932-33 session have just been published, on 